\title{
La mediación como solución de conflictos o mera expectativa: enfoque de análisis a resultados de procesos atendidos en varios centros de mediación. Guayaquil-Ecuador \\ Mediation as a conflict solution or mere expectation: analysis approach to the results of processes attended in several mediation centers. Guayaquil-Ecuador
}

\author{
MSc, Washington René Astudillo Orellana ${ }^{1}$ \\ rastudillo@hotmail.com \\ MSc, Mercedes Patricia Rodríguez Sandoval ${ }^{2}$ \\ parosan@hotmail.es
}

Recibido: 1/04/2018, Aceptado: 1/06/2018

\begin{abstract}
RESUMEN
De entre los medios para solucionar los conflictos de intereses jurídicamente trascendentes se encuentra la heterocomposición, donde la solución va a provenir de un tercero ajeno a la controversia, por lo que se califica de imparcial. Dentro de la heterocomposición se encuentra la mediación, un medio de solución de conflictos que no busca suplir a la función judicial sino más bien complementarla, pues además de contribuir a la descongestión de los jueces y tribunales ejercita los principios de mínima intervención penal, subsidiariedad y economía procesal. Como dijo Séneca: "Nada se parece tanto a la injusticia como la justicia tardía".
\end{abstract}

Palabras clave: mediación, heterocomposición, subsidiariedad, extrajudicial

\section{ABSTRACT}

Among the means to solve legally significant conflicts of interest is the hetero composition, where the solution will come from a third party outside the controversy, so it is described as impartial. Within the hetero composition is mediation, a means of conflict resolution that does not seek to replace the judicial function, but rather complements it, because in addition to contributing to the decongestion of judges and courts, it exercises the principles of minimum criminal intervention, subsidiarity and procedural economy. As Seneca said: "Nothing is as much like injustice as late justice."

Keywords: mediation, heterocomposition, subsidariety, extrajudicial

\footnotetext{
1 Universidad de Guayaquil, Ecuador

2 Universidad de Guayaquil, Ecuador
} 


\section{Introducción}

Aristóteles entendió desde tiempos inmemorables que el hombre es un zoon politikón; es decir un animal político por naturaleza y necesita entablar relaciones comerciales, amorosas, laborales con otros, pero no siempre existe un acuerdo de intereses entre estos dos sujetos, pues asimismo por la propia astucia del hombre que busca imponer su pretensión sobre la de los demás sin importar a quien se lleve por el camino, surge como respuesta el Derecho, como la ciencia de la justo, de darle a cada quien lo que se merece y tratar de vivir en armonía.

Sin embargo, si el Estado en su función jurisdiccional entraría a resolver cada uno de los conflictos jurídicamente trascendentes que se suscitan en la sociedad quedaría agobiado y fuese totalmente ineficiente; debido a esto es que surge la Mediación, como solución de conflictos extrajudicial, fuera de todo el aparataje burocrático, en donde las partes por muto consentimiento designan a un tercero imparcial fuera del conflicto denominado mediador, para que propicie la comunicación entre las partes y así poder llegar a un acuerdo que resuelva el conflicto; asimismo Guamán Burneo establece que la mediación es un método no adversarial, pues no se trata de que una las partes gane o pierda, sino de que recíprocamente cedan hasta llegar a un punto de equilibrio beneficioso para ambas, sin tener que esperar las dilaciones y el tiempo engorroso que lleva un proceso dentro de la función judicial (Burneo, 2011).

En los conflictos individuales, donde las partes involucradas en la litis, puedan disponer de sus bienes y derechos, en pro del logro y solucionar la pugna que los confronta, y en la mayoría de los casos los propios abogados pueden contribuir a establecer la comunicación directa entra las partes y/o justiciables, a fin de encontrar una solución negociada pero justa.

\section{Desarrollo}

Al referirnos a la mediación como un alternativa, que se lleva a cabo desde el mismo interés individual y común a la vez entre los mediados, podemos pensar en justicia pura, es decir creamos una meta proyección que acapara la atención, por ser una especie de real solución dentro del convulsionado enlace de sentimientos, reacciones, posiciones, estragos propios del conflicto, que lejos de coadyuvar en una verdadera solución, nos enfoca en dimensiones grandes, al estado deseado de querer alcanzar una paz social, que no siempre va a depender de la buena voluntad sino del realismo puro en que las partes se traban y que no les permite pensar más allá de sus emociones latentes.

Una buena parte de estas expresiones, se la damos como carga pesada al mediador, quien si bien es una figura importantísima dentro del referido proceso de mediación, no es quien soluciona ni resuelve las controversias, sino más bien, es quien conduce a pasos firmes el desarrollo de esta emotivas intervenciones, creando una atmósfera propicia para que el encuentro, muchas veces poco agradable, resulte beneficioso y productivo, al alcanzar las soluciones auto compuestas que terminen el litigio y abra canales de diálogo para llegar al consenso y posterior acuerdo.

Los Dres. Juan Pedro Coleiro y Jorge A. Rojas, en su libro "Mediación Obligatoria y Audiencia preliminar" (Coleiro y Rojas, 1998) hacen un recuento sobre las particularidades de la Ley de Mediación y Conciliación Obligatoria, como que entre 


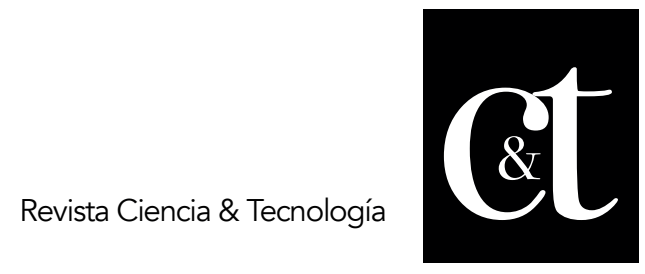

No. 19, 31 de julio de 2018

ISSN impreso: 1390 - 6321

los requisitos para ser mediador se necesita poseer título de abogado así como adquirir la capacitación otorgada en cursos para mediadores; más aún si se trata de conflictos en los que esté inmerso el Estado y comprometidos fondos públicos, sin perjuicio de que auxiliares interdisciplinarios puedan colaborar con el mediador, creando así registros en los que se atienden causas, casos o procesos en donde claramente se advierte la preparación y formación de quien asiste en calidad de mediador.

Estos procesos, han contribuido enormemente en la descongestión de la función judicial en términos de administración de justicia, pues podemos advertir que un acuerdo de mediación, concluye con la firma de diversas Actas, las que de lograrse los esperados acuerdos, constituyen efectos de sentencia ejecutoriada en calidad de cosa juzgada, avance legal que ha contagiado a muchos actores de estos procesos, haciendo eco en otros que desean erradicar las lesiones que un juicio acarrea en los involucrados en situaciones conflictivas.

Tomando este antecedente, se plantea como problema de investigación, si la mediación es en realidad una solución o estamos frente a una mera expectativa, enfocando el presente artículo científico en tres casos específicos, tomados al azar de varios Centros de Mediación en la ciudad de Guayaquil, puerto principal del Ecuador.

La causa de esta problemática tiene como principal referencia, que la mediación es parte activa de un conjunto de normativa jurídica y principios que deben atenderse dentro del procedimiento establecido para ello, lo cual produce un importante impacto de seguridad en la sociedad, dentro de la conocida administración de justicia, pues estos procedimientos ofrecen eficiencia, calidad, rapidez y soluciones mediatas e inmediatas (Folberg, 2012).

La mediación es conocida y aplicada mundialmente y en cada país o región se imponen características propias de acuerdo a su particular legislación, pero siempre está llevada a cabo con la finalidad de contribuir con la sociedad en celeridad procesal, ahorrando tiempo, dinero y proveyendo de eficiencia y eficacia conforme a la calidad de los servicios que se ofertan para ello (Moore, 2010). En Ecuador se tiene como fundamento, el Art. 190 de la Constitución de la República y se refiere la regulación de su procedimiento, en la Ley de Arbitraje y Mediación.

La investigación está plenamente justificada, porque la mediación al tener su propio proceso, se la puede clasificar dependiendo de la perspectiva desde la cual se analice:

- Puede ser bilateral o multilateral (dependiendo del número de mediados).

- Pública o privada: Esta división se basa en la calidad de los órganos que forman los centros de mediación por Ej. El Centro de mediación de una Universidad o de la Cámara de Comercio de Guayaquil son privados mientras que el Centro de mediación y negociación del municipio distrital de Quito o del Consejo de la Judicatura son públicos.

- Desde el Área o materia: Familiar, laboral, penal, comercial.

- Si se considera un elemento extranjero: Internacional o Nacional.

- Finalmente, según la ubicación de los centros de mediación adscrita a la función judicial y extrajudicial. 


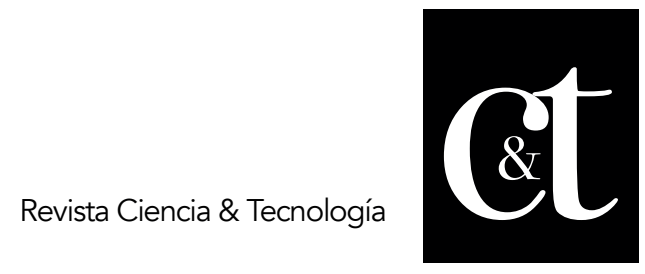

No. 19, 31 de julio de 2018

ISSN impreso: 1390 - 6321

Algunos autores hablan de que la mediación judicial es eminentemente pública y la extrajudicial privada (Burneo, 2011).

A ello no se podría colegir que esta división o clasificación sea la causa para que se incrementen los procesos en mediación, pues mucho tiene que ver la calidad de los servicios que se ofertan y el desenvolvimiento y desarrollo del tercero neutral llamado mediador, a quien se le atribuye la carga de conducir los procesos, generando confianza y empatía que mueva a las partes a conocer sus realidades, a aceptarlas y querer mejorar la situación logrando acuerdos aceptables en sus intereses y necesidades. En el análisis y estudio científico actual, se han observado tres casos diferentes con la finalidad de cubrir el principal objetivo de la investigación.

En el Ecuador, varios cuerpos normativos hacen mención a la mediación, como método voluntario de solución de conflictos extrajudicial sobre materia transigible. El Código Civil con la transacción (primer inciso del Art 2348); COGEP Arts. 294, 363, 153, 102; COIP (mediación entre la víctima y el adolescente Art 347), Código Orgánico de la Producción, Código del Trabajo, pero únicamente en el caso sobre la forma del cumplimiento de las obligaciones laborales.

La Ley Orgánica del Sistema Nacional de Contratación Pública, establece la posibilidad que en el caso de que "surtan controversias entre las partes contratantes se buscarán solucionarlas de forma ágil, rápida y directa a través de los mecanismos de solución de controversias contractuales previstos en la ley, conciliación y/o transacción". Por ejemplo: el Instituto Nacional de Compras Públicas contempla dentro de los pliegos de contratación a la mediación como solución en caso de existir posibles conflictos derivados de la ejecución de los contratos.

Por otro lado, el COGEP establece que el juez, durante la audiencia preliminar en procedimientos ordinarios, de oficio, o a petición de parte, podrá disponer que la controversia pase a un centro de mediación legalmente constituido, para que se busque un acuerdo entre las partes. En caso de que las partes suscriban un acta de mediación en la que conste un acuerdo total, la o el juzgador la incorporará al proceso para darlo por concluido.

Guamán Burneo, establece que el mediador que resuelve conflictos del sector público se vuelve un defensor del patrimonio estatal y debe conocer al menos los principios generales del derecho procesal como de contratación pública, esto como garantía de que va a existir el justo manejo de conflicto de intereses (Burneo, 2011).

A diferencia de la normativa de otros países donde se establecen las obligaciones del mediador como de instar a las partes a que presenten fórmulas de arreglo o a levantar el acta de audiencia y a registrarla en un centro de mediación no ocurre lo mismo en nuestra actual Ley de Arbitraje y Mediación, donde se le deja a la discrecionalidad del centro de mediación los requisitos de los mediadores, sin saber si están siguiendo un eficiente proceso de formación.

El Abg. Guamán Burneo, llega a la conclusión que en el tema de contratación pública, el representante del Estado y el particular no llegan a acuerdos de 
mediación con la frecuencia necesaria para evitar la congestión de la función judicial, y a su vez desincentiva los contratos y la posibilidad de inversión con el Estado, pues el funcionario público teme que por optar por la mediación sea sujeto de una glosa por parte de la Controlaría General del Estado por la forma en que se llegaron a los acuerdos de mediación. Asimismo, Guamán Burneo propone que este obstáculo podría ser superado con la intervención y vigilancia de la PGE y de la CGE para asegurar la seguridad jurídica y la seguridad económica respectivamente (Burneo, 2011).

El reconocimiento constitucional de la mediación permite el empoderamiento del ciudadano y fortalece la idea de un Estado garantista de derechos y justicia, pues se deja a un lado la vieja idea de la superioridad del Estado sobre los administrados y que el individuo no era lo suficientemente capaz de solucionar conflictos que se suscitaban entre ellos pues necesitaba siempre del Estado (doctrina de tutelaje).

Ergo, Guamán Burneo establece que la mediación reafirma la razón de ser del servidor público que no es más que el que servir/ayudar a los administrados y que mejor forma de hacerlo desde el propio Estado con el diálogo antes que en un juicio (Burneo, 2011). Con ello acrece la labor del mediador que debe tener dotes y vocación de servicio.

Frank Moderne (2004) afirma: "la administración no es un mero aparato mecánico de ejecución de la ley, es, sobre todo, un poder, un poder que tiene encomendada la gestión de los intereses comunes de los ciudadanos". Es decir, de nada sirve el reconocimiento de los derechos en la Constitución sino hay una política pública que impulse su respectiva aplicación.

Con el paso del tiempo, la demanda de los centros de mediación se ha ido incrementado, pues desde la formalización de los medios alternativos de solución de conflictos en un texto normativo como la Ley de Arbitraje y Mediación en 1997 y el reconocimiento en la CRE de 2008, la ciudadanía ha tenido mayor confianza en su aplicación.

Algunos autores no le ven sentido de ser a la mediación dentro de los trámites administrativos, pues en caso de controversias contractuales, el Estado tiene la posibilidad de rescindir del mismo junto a los efectos jurídicos que provoca. Sin embargo, Guamán Burneo establece que el contrato administrativo debe ser considerado como un negocio para el particular, asegurando la igualdad de oportunidades y equilibrio financiero de ambas partes, pues el contratista es un colaborador y más no un subordinado del Estado al cual se le deben ofrecer una serie de garantías mínimas que lo incentiven a contratar y no someterlo por el contrario a una única vía dificultosa y tediosa para reclamar sus derechos como lo es el proceso contencioso administrativo (Burneo, 2011).

A diferencia de la mediación en el sector privado, la mediación en el público se rige estrictamente en derecho y el acto suscrita del acuerdo debe ser autorizada por un delegado del PGE junto con una serie de pruebas que acrediten los hechos base de las pretensiones, todo esto para salvaguardar la seguridad jurídica y evitar un posible detrimento al patrimonio público.

En el caso colombiano se prevé la creación de los comités de conciliación en la 


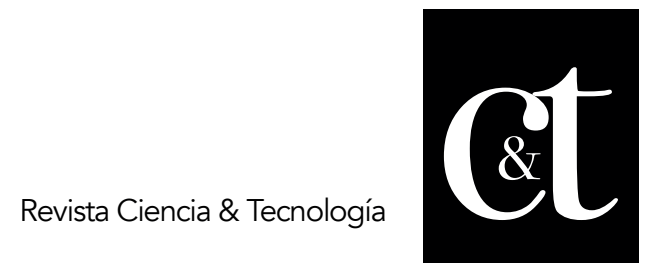

No. 19, 31 de julio de 2018

ISSN impreso: 1390 - 6321

mayoría de las entidades estatales, sin embargo, el mediador pertenecía a la misma Administración, es decir se convertía en juez y parte, poniendo en una seria duda la imparcialidad y neutralidad del mediador.

Asimismo Guamán B, establece que dentro de los contratos de contratación pública si se encuentra la redacción de cláusulas de solución alternos de conflictos o controversias en la interpretación o ejecución del contrato, sin embargo, la mediación se vuelve de carácter potestativo a las partes y no obligatorio, lo que reforzaría como primer opción al diálogo de manera ineludible, y no como una posibilidad, que por la costumbre litigiosa que se mantiene en nuestro país es cada vez más remota (Burneo, 2011).

El Ministerio de Justicia a través de ProJusticia año tras año ha intervenido en la difusión de los mismos a nivel nacional por varios medios a diferentes estratos de la población, sin embargo la misma ha sido esporádica y ha tenido su respuesta ante un proyecto determinado, siendo su continuidad lo que ha faltado; sin embargo, es importante que los diferentes centros de mediación privados coadyuven en esta labor para que ambos sectores público y privado sean los promotores de este beneficio dirigido a la sociedad en general. Asimismo, según el Censo Nacional de Centros de Mediación en Ecuador, contratado por ProJusticia, éstos son insuficientes en comparación con el número de habitantes por provincia (Burneo, 2011).

El Abg. Guamán Burneo alega que, a pesar de existir una creciente concurrencia a los diversos centros de mediación, no existe voluntad política por parte del Estado, ya sea propia de los jueces o miembros de la función judicial que mantienen el recelo de enviar los procesos a los centros de mediación por la posible falta de trabajo, y por parte del propio Estado al no destinar los suficientes fondos para su implementación.

El descongestionamiento en las Cortes y Ministerios no se resuelve creando más dependencias o cambiando de funcionarios, sino más bien cambiado la idea de justicia de raíz, donde el único medio de solución de conflictos efectivo es un juicio largo que implica desgaste emocional y económico, así como a abogados que prolongan innecesariamente procesos administrativos y judiciales a un sistema rápido, eficiente, pacífico y con soluciones que nazcan de las partes (Burneo, 2011).

\section{Materiales y métodos}

El abordaje que se da con profundo análisis sobre el fenómeno estudiado permite observar que, dentro de las ciencias sociales, éstos son diversos, según lo exponen Taylor y Bodgan (2014), pues permiten identificar los hechos más relevantes dentro del estudio de casos, identificando las causas establecidas y vinculadas al problema materia de la presente investigación.

Con ello se trató de investigar de dónde proviene la solución auto compuesta, si de las partes o del mediador; aplicando la metodología fenomenológica, que para Martínez (2014), analiza los aspectos más relevantes sobre un punto u objeto específico y en un tiempo y espacio determinado. En la presente investigación, se observaron en los principales Centros de Mediación de la ciudad de Guayaquil, con un enfoque cualitativo. La pertinencia del tema promovió utilizar la investigación interpretativa que conlleva una identificación a la problemática social por parte de los actores principales de los procesos estudiados en los Centros de Mediación de la 
ciudad de Guayaquil, habiéndose observado, analizado e interpretado la opinión y expresiones de los intervinientes y sobre el servicio recibido en la mediación, de acuerdo a los resultados obtenidos y/o esperados (Alvarado y García, 2013).

Se ha incluido en la presente investigación, bibliografía documental, con revisión de documentos legales, textos y artículos en pleno contraste con el estudio de campo realizado en base al enfoque cualitativo sobre estas ciencias sociales y los hallazgos obtenidos.

La técnica de la investigación cualitativa hizo referencia a la entrevista, realizada a los mediados de los tres casos específicos que alcanzaron acuerdos en tres principales Centros de mediación y se utilizó como instrumento una guía previamente estructurada para recopilación de la información (Murillo, 2014).

Al tratarse de estudios de casos, la población y muestra de la investigación, fueron las mismas, habiéndose entrevistado a 7 personas que acudieron a los Centros de Mediación por casos específicos en números de 2 usuarios por cada caso, donde se puso como relevancia, los principios generales de la mediación, para obtener la información sobre los resultados esperados, en comparación con las expectativas que llevaron al momento de solicitar los servicios de mediación en los Centros observados. 


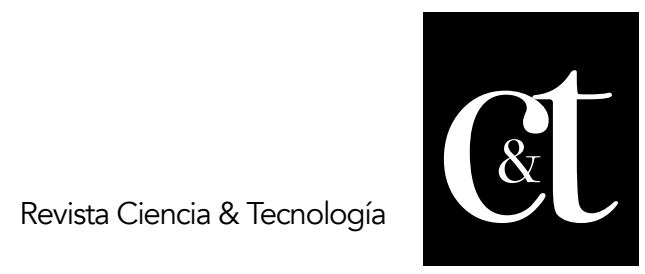

No. 19, 31 de julio de 2018

ISSN impreso: 1390 - 6321

Tabla 1: Principios generales de la mediación

\begin{tabular}{|c|c|c|c|}
\hline Voluntariedad & onfidencialidad & Flexibilidad & Neutralidad \\
\hline 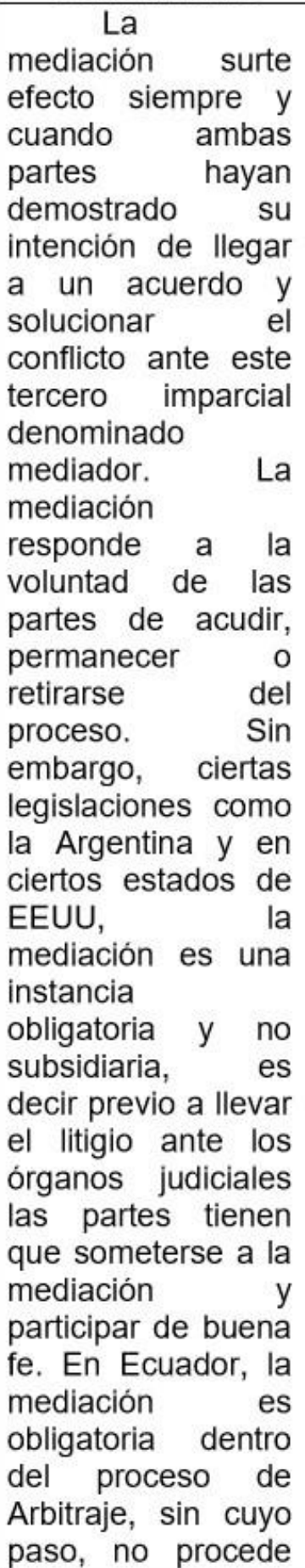 & \begin{tabular}{l}
\multicolumn{2}{c}{ La } \\
mediación la \\
involucra \\
confidencialidad \\
del mediador y de \\
los mediados, así \\
como de \\
cualquier otra \\
persona \\
vinculada a la \\
misma, es decir, \\
lo tratado en la \\
mediación no \\
podrá na ser \\
divulgado por el \\
mediador ni \\
podrá ser llamado \\
a declarar en \\
juicio sobre el \\
conflicto objeto \\
de la mediación, \\
a excepción de \\
que se presuma \\
la existencia de \\
un delito.
\end{tabular} & \begin{tabular}{lr}
\multicolumn{2}{c}{ La } \\
mediación, es un \\
método de \\
solución de \\
conflictos que \\
actúa como \\
auxilio de la \\
función judicial, \\
por lo que sería \\
incompatible que \\
la mediación se \\
someta una serie \\
de etapas y \\
reglas que \\
prolonguen el \\
procedimiento \\
más que la \\
propia justicia \\
ordinaria. Perse \\
el mediador y en \\
si los \\
involucrados y/o \\
mediados, \\
pueden prevenir \\
gestiones \\
convertir la forma \\
en que se \\
desenvolverá \\
más eficazmente \\
la comunicación \\
en pro de un \\
resultado.
\end{tabular} & 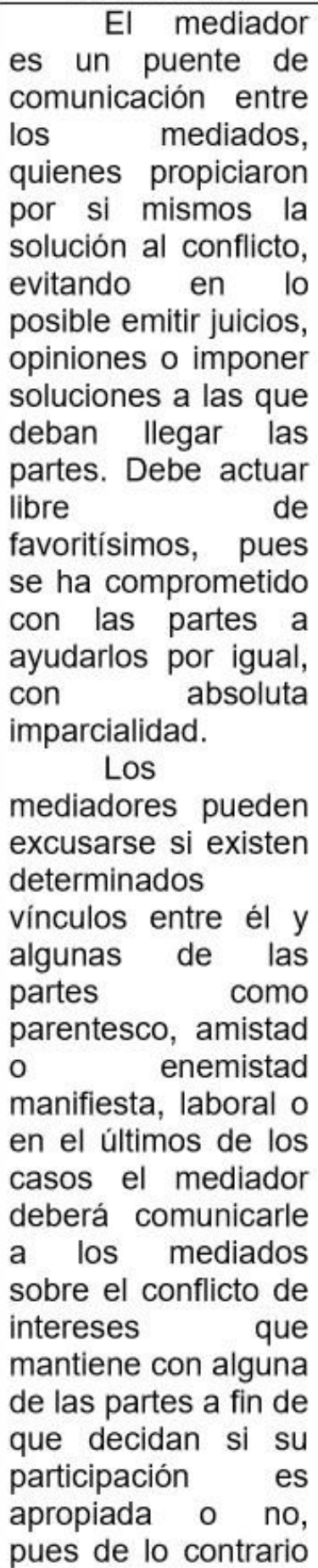 \\
\hline
\end{tabular}




\begin{tabular}{|c|c|}
\hline $\begin{array}{l}\text { continuar con el } \\
\text { arbitraje, } \\
\text { entendiéndose que } \\
\text { es el proceso de } \\
\text { mediación el } \\
\text { obligatorio, mas no } \\
\text { que las partes } \\
\text { lleguen a un } \\
\text { acuerdo, a menos } \\
\text { que esa sea su } \\
\text { voluntad. }\end{array}$ & $\begin{array}{l}\text { viciaria el principio } \\
\text { de voluntariedad } \\
\text { imprescindible en la } \\
\text { mediación. } \\
\text { velará mediador } \\
\text { honestidad, porque } \\
\text { la mediación se } \\
\text { desarrolle bajo los } \\
\text { principios de } \\
\text { equidad, legalidad } \\
\text { (recaen únicamente } \\
\text { materia transigible, } \\
\text { es decir que no } \\
\text { sobrepongan de de } \\
\text { derechos } \\
\text { terceros y del interés } \\
\text { público). }\end{array}$ \\
\hline
\end{tabular}

Tabla 2: Entrevista a mediados que concurrieron a los Centros de Mediación.

\begin{tabular}{|c|c|c|c|c|c|c|c|}
\hline \multirow{2}{*}{$\begin{array}{l}\text { Ite } \\
\mathrm{m}\end{array}$} & \multirow{2}{*}{$\begin{array}{l}\text { Pregunta } \\
\mathbf{s}\end{array}$} & \multirow[b]{2}{*}{ Usuario 1} & \multirow[b]{2}{*}{$\begin{array}{c}\text { Usuario } \\
2\end{array}$} & \multirow{2}{*}{$\begin{array}{c}\text { Usuario } \\
3\end{array}$} & \multirow[b]{2}{*}{ Usuario 4} & \multirow[b]{2}{*}{ Usuario 5} & \multirow[b]{2}{*}{$\begin{array}{c}\text { Categoria } \\
\mathbf{s}\end{array}$} \\
\hline & & & & & & & \\
\hline 1 & $\begin{array}{l}\text { ¿El } \\
\text { mediador } \\
\text { presentó } \\
\text { las reglas } \\
\text { de } \\
\text { procedimi } \\
\text { ento al } \\
\text { inicio del } \\
\text { proceso } \\
\text { de } \\
\text { mediación } \\
?\end{array}$ & $\begin{array}{l}\text { No fue tan } \\
\text { claro, pero } \\
\text { se } \\
\text { presentó e } \\
\text { identificó } \\
\text { nuestros } \\
\text { nombres }\end{array}$ & $\begin{array}{l}\text { No } \\
\text { entendi } \\
\text { bien lo } \\
\text { que decia }\end{array}$ & $\begin{array}{l}\text { Creo } \\
\text { que hizo } \\
\text { bien su } \\
\text { trabajo }\end{array}$ & $\begin{array}{l}\text { Sl lo hizo, } \\
\text { pero fue } \\
\text { muy } \\
\text { rápido al } \\
\text { explicar }\end{array}$ & $\begin{array}{ll}\text { Si } & \\
\text { Creo que } \\
\text { lo hizo } \\
\text { bien }\end{array}$ & $\begin{array}{l}\text { No fue } \\
\text { claro } \\
\text { (poco } \\
\text { nivel de } \\
\text { claridad y } \\
\text { concrecio } \\
\text { n) }\end{array}$ \\
\hline 2 & $\begin{array}{l}\text { ¿Promovi } \\
\text { o una } \\
\text { comunicac } \\
\text { ión clara y } \\
\text { abierta, } \\
\text { enfocando } \\
\text { la } \\
\text { necesidad } \\
\text { de }\end{array}$ & $\begin{array}{l}\text { Trataba } \\
\text { de } \\
\text { concretar } \\
\text { acuerdos } \\
\text { muy } \\
\text { rápidamen } \\
\text { te }\end{array}$ & $\begin{array}{l}\text { El } \\
\text { problema } \\
\text { lo } \\
\text { sablamos } \\
\text { nosotros, } \\
\text { pero se } \\
\text { podia } \\
\text { trabajar } \\
\text { aún más }\end{array}$ & $\begin{array}{l}\text { No fue } \\
\text { muy } \\
\text { clara la } \\
\text { comunic } \\
\text { ación en } \\
\text { realidad }\end{array}$ & $\mathrm{Si}$ & $\begin{array}{l}\text { Explicó } \\
\text { varias } \\
\text { cosas de } \\
\text { cómo } \\
\text { seria el } \\
\text { proceso, } \\
\text { y a cada } \\
\text { momento } \\
\text { nos pedia }\end{array}$ & $\begin{array}{l}\text { Confusión } \\
\text { (bajo nivel } \\
\text { de } \\
\text { claridad y } \\
\text { concreció } \\
\text { n) }\end{array}$ \\
\hline
\end{tabular}




\begin{tabular}{|c|c|c|c|c|c|c|c|}
\hline & $\begin{array}{l}\text { transparen } \\
\text { tar el } \\
\text { problema? }\end{array}$ & & $\begin{array}{l}\text { para } \\
\text { entender } \\
\text { mejor la } \\
\text { situación } \\
\text { desde el } \\
\text { punto de } \\
\text { vista del } \\
\text { tercero } \\
\text { neutral }\end{array}$ & & & $\begin{array}{l}\text { que } \\
\text { concretár } \\
\text { amos }\end{array}$ & \\
\hline 3 & $\begin{array}{l}\text { ¿Formó } \\
\text { parte del } \\
\text { fondo del } \\
\text { conflicto o } \\
\text { se } \\
\text { mantuvo } \\
\text { distante } \\
\text { de él y de } \\
\text { ustedes? }\end{array}$ & $\begin{array}{l}\text { Le faltó } \\
\text { poder de } \\
\text { persuasió } \\
n \text { y } \\
\text { convenci } \\
\text { miento. }\end{array}$ & $\begin{array}{l}\text { Su } \\
\text { trabajo } \\
\text { fue } \\
\text { bueno } \\
\text { pero } \\
\text { nosotros } \\
\text { esperába } \\
\text { mos que } \\
\text { él nos dé } \\
\text { pautas } \\
\text { pero } \\
\text { siempre } \\
\text { estuvo } \\
\text { distante. } \\
\text { No } \\
\text { sabíamos } \\
\text { si pedirle } \\
\text { que nos } \\
\text { ayude un } \\
\text { poco mas }\end{array}$ & $\begin{array}{l}\text { Le } \\
\text { solicitam } \\
\text { os } \\
\text { ayuda } \\
\text { pero nos } \\
\text { explicó } \\
\text { que él } \\
\text { debía } \\
\text { ser } \\
\text { imparcial }\end{array}$ & $\begin{array}{l}\text { No, hubo } \\
\text { involucra } \\
\text { miento de } \\
\text { él en el } \\
\text { conflicto, } \\
\text { sólo nos } \\
\text { orientaba } \\
\text { a aclarar } \\
\text { aspectos } \\
\text { important } \\
\text { es y a } \\
\text { definir } \\
\text { situacione } \\
\text { s futuras } \\
\text { con lo } \\
\text { que } \\
\text { llegaríam } \\
\text { os al } \\
\text { acuerdo }\end{array}$ & $\begin{array}{l}\text { Fue algo } \\
\text { cortés } \\
\text { pero } \\
\text { siempre } \\
\text { se sentía } \\
\text { su } \\
\text { distancia } \\
\text { miento a } \\
\text { involucrar } \\
\text { se en el } \\
\text { conflicto. }\end{array}$ & Apatía \\
\hline 4 & $\begin{array}{l}\text { ¿Asumió } \\
\text { su rol de } \\
\text { facilitador, } \\
\text { despejand } \\
\text { o } \\
\text { acertadam } \\
\text { ente todas } \\
\text { sus dudas } \\
\text { durante el } \\
\text { proceso } \\
\text { de } \\
\text { mediación } \\
?\end{array}$ & $\begin{array}{l}\text { Fue más o } \\
\text { menos } \\
\text { llevado el } \\
\text { proceso, } \\
\text { no se } \\
\text { aclararon } \\
\text { muchas } \\
\text { de } \\
\text { nuestras } \\
\text { dudas, } \\
\text { faltó } \\
\text { tiempo }\end{array}$ & $\begin{array}{l}\text { Si } \\
\text { hubiéram } \\
\text { os tenido } \\
\text { un poco } \\
\text { más } \\
\text { tiempo } \\
\text { podríamo } \\
\text { s haber } \\
\text { despejad } \\
\text { o tantas } \\
\text { dudas } \\
\text { propias } \\
\text { de } \\
\text { nuestro } \\
\text { problema }\end{array}$ & $\begin{array}{l}\text { Sí. Pero } \\
\text { entende } \\
\text { mos que } \\
\text { no es } \\
\text { función } \\
\text { de él } \\
\text { buscar } \\
\text { la } \\
\text { solución } \\
\text { y } \\
\text { nosotros } \\
\text { tampoco } \\
\text { la } \\
\text { encontra } \\
\text { mos, por } \\
\text { eso no } \\
\text { logramo } \\
\text { s } \\
\text { acuerdo } \\
\text { s }\end{array}$ & $\begin{array}{l}\text { Fue } \\
\text { demasiad } \\
\text { o } \\
\text { imparcial } \\
\text { y no se } \\
\text { inmiscuyó } \\
\text { realmente } \\
\text { en el } \\
\text { conflicto } \\
\text { ni en los } \\
\text { acuerdos }\end{array}$ & $\begin{array}{l}\text { Fue } \\
\text { imparcial, } \\
\text { pero sin } \\
\text { fuerza o } \\
\text { sea que si } \\
\text { hubiera } \\
\text { sido un } \\
\text { poco más } \\
\text { enérgico } \\
\text { hubiéram } \\
\text { os } \\
\text { aprovech } \\
\text { ado mejor } \\
\text { el tiempo }\end{array}$ & $\begin{array}{l}\text { No } \\
\text { comprome } \\
\text { tido con } \\
\text { su papel }\end{array}$ \\
\hline
\end{tabular}




\begin{tabular}{|c|c|c|c|c|c|c|c|}
\hline 5 & $\begin{array}{l}\text { ¿Siente } \\
\text { que todo } \\
\text { estuvo } \\
\text { claro o } \\
\text { necesitab } \\
\text { a algo } \\
\text { adicional } \\
\text { para } \\
\text { fortalecer } \\
\text { las } \\
\text { decisiones } \\
?\end{array}$ & $\begin{array}{l}\text { Realment } \\
\text { e } \\
\text { esperaba } \\
\text { algo más } \\
\text { de la } \\
\text { mediación } \\
\text { tal vez } \\
\text { que el } \\
\text { Mediador } \\
\text { estuviera } \\
\text { un poco } \\
\text { más } \\
\text { empodera } \\
\text { do del } \\
\text { tema } \\
\text { concreto } \\
\text { del } \\
\text { problema. }\end{array}$ & $\begin{array}{l}\text { El } \\
\text { mediador } \\
\text { necesitab } \\
\text { a mucha } \\
\text { informaci } \\
\text { ón acerca } \\
\text { del } \\
\text { conflicto } \\
\text { nuestro y } \\
\text { eso me } \\
\text { agotó. }\end{array}$ & $\begin{array}{l}\text { Necesita } \\
\text { ba un } \\
\text { poco } \\
\text { más de } \\
\text { atención } \\
\text { y que el } \\
\text { mediado } \\
r \text { de } \\
\text { alguna } \\
\text { manera } \\
\text { nos } \\
\text { oriente } \\
\text { sobre si } \\
\text { estábam } \\
\text { os bien } \\
\text { en } \\
\text { nuestras } \\
\text { percepci } \\
\text { ones o } \\
\text { no. }\end{array}$ & $\begin{array}{l}\text { Si yo creo } \\
\text { que él } \\
\text { estuvo } \\
\text { bien, } \\
\text { quizás si } \\
\text { nosotros } \\
\text { hubiéram } \\
\text { os } \\
\text { cambiado } \\
\text { las } \\
\text { actitudes, } \\
\text { hubiéram } \\
\text { os } \\
\text { logrado al } \\
\text { menos un } \\
\text { acuerdo. }\end{array}$ & $\begin{array}{l}\text { Estuvo } \\
\text { bien, pero } \\
\text { pudo ser } \\
\text { mejor. } \\
\text { Falto } \\
\text { mucha } \\
\text { informaci } \\
\text { ón de } \\
\text { parte y } \\
\text { parte }\end{array}$ & $\begin{array}{l}\text { Incomunic } \\
\text { ación. de } \\
\text { Falta de } \\
\text { preparació } \\
n \text { en } \\
\text { temas relevantes } \\
\text { revel }\end{array}$ \\
\hline 6 & $\begin{array}{l}\text { ¿Consider } \\
\text { a usted } \\
\text { que se } \\
\text { logra } \\
\text { desconge } \\
\text { stionar la } \\
\text { función } \\
\text { judicial la } \\
\text { con la } \\
\text { existencia } \\
\text { de los } \\
\text { mecanism } \\
\text { os alternos } \\
\text { de solución } \\
\text { de } \\
\text { conflictos } \\
\text { atendidos } \\
\text { en los } \\
\text { Centros } \\
\text { de } \\
\text { Mediación } \\
\text { ? }\end{array}$ & $\begin{array}{l}\text { ¿Pienso } \\
\text { que si, } \\
\text { pero que } \\
\text { pasa si los } \\
\text { acuerdos } \\
\text { que } \\
\text { firmamos } \\
\text { hoy, no se } \\
\text { cumplen? } \\
\text { Debemos } \\
\text { regresar a } \\
\text { la función } \\
\text { judicial } \\
\text { para pedir } \\
\text { la ejecución } \\
\text { ejecu acta } \\
\text { del firmada }\end{array}$ & $\begin{array}{l}\text { Si. } \\
\text { Es } \\
\text { ventajoso } \\
\text { tener otra } \\
\text { instancia } \\
\text { para } \\
\text { resolver } \\
\text { nuestros } \\
\text { problema } \\
\text { s, pero } \\
\text { los } \\
\text { mediador } \\
\text { es deben } \\
\text { trabajar } \\
\text { mejor los } \\
\text { acuerdos } \\
\text { para } \\
\text { asegurar } \\
\text { el } \\
\text { cumplimi } \\
\text { nento, } \\
\text { caso } \\
\text { contrario, } \\
\text { regresam } \\
\text { os a la } \\
\text { función } \\
\text { judicial }\end{array}$ & $\begin{array}{l}\text { Sí, creo } \\
\text { que sí. }\end{array}$ & $\begin{array}{l}\text { Puede ser } \\
\text { porque si } \\
\text { hemos } \\
\text { llegado a } \\
\text { acuerdos } \\
\text { y estos se } \\
\text { cumplen, } \\
\text { ahí } \\
\text { termina } \\
\text { todo. }\end{array}$ & $\begin{array}{l}\text { No es } \\
\text { suficiente. } \\
\text { Los } \\
\text { jueces no } \\
\text { toman el } \\
\text { control } \\
\text { total y } \\
\text { cuando } \\
\text { no nos } \\
\text { cumplen } \\
\text { los } \\
\text { acuerdos } \\
\text { debemos } \\
\text { acudir vez } \\
\text { otra vez } \\
\text { donde los } \\
\text { jueces. }\end{array}$ & $\begin{array}{l}\text { Insegurida } \\
\text { d juridica }\end{array}$ \\
\hline
\end{tabular}




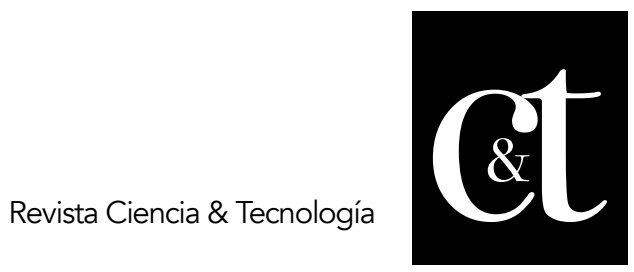

No. 19, 31 de julio de 2018

ISSN impreso: 1390 - 6321

Del estudio realizado, se ha podido colegir los aspectos importantes de la presente investigación, es decir, que se logró identificar que está en las mismas partes, la necesidad de contribuir en la solución de sus desavenencias, sin embargo, éstas perduren en comprometer siempre la opinión, palabra y decisión del mediador; pues, a pesar que existen principios básicos y generales de la mediación y que éstos son repetidos en cada uno de los procesos y en cada una de las audiencias, las partes requieren el apoyo constante y permanente de la figura neutral.

Respecto de la fase de descongestionamiento de la función judicial, ha quedado evidenciado que, si existe tal beneficio y ventaja, pero hay que trabajar de mejor manera los acuerdos a fin de que éstos por sí mismos se cumplan, no siendo necesario que las partes pidan su ejecución, porque entonces tal descongestionamiento no existe y todos volverán a la función judicial. Es decir, se debe ganar una total y absoluta confianza de la ciudadanía en los procesos de mediación, a lo que se suma la totalidad de los buenos servicios que se deben ofrecer para ganar la ansiada empatía de las partes y que el mediador trabaje en terreno firme y seguro de que los acuerdos a los que lleguen las partes lleven impresa en la mente de los mediados, la garantía de su fiel cumplimiento.

De los resultados analizados, se observa aún apatía y confusión por parte de quienes acuden a trabajar sus procesos de mediación, esto por desconocimiento de lo que es la mediación, cómo opera y las garantías que revisten este proceso, sin embargo también se observa la falta de compromiso de parte del mediador que extiende hasta confundir su escudo de neutralidad e imparcialidad, que lo limitan o frenan a despojarse de esa fuerza que lo mantiene aún atado a los principios de confidencialidad y extrema neutralidad.

También se ha observado y evidenciado algo de inseguridad jurídica al momento de entrevistar a las partes que acudieron a los Centros de Mediación, cuando manifiestan que no están seguros de los acuerdos firmados y manifiestan un poco de preocupación sobre los posibles incumplimientos a los acuerdos suscritos.

En contraste de los resultados que se han obtenido, en los tres casos estudiados, los mediados perciben que no siempre hay empatía y por tanto se crea un poco la desconfianza, lo cual limita a las partes a explayar sus problemas, temores y emociones. Los procesos se llevan bien pero aún persiste la incomunicación de los mediados, lo cual denota clara afectación en la parte humana y emocional que debe atenderse también en estos procesos (Zelaya, Kuesterman y Armas, 2013).

Pese a todos los inconvenientes que se han identificado, en los tres casos investigados, se lograron acuerdos importantes, con lo que se logró terminar con tres conflictos y se puso fin a las controversias generadas, ya que los conflictos se pueden generar por percepciones ocultas pero así mismo se pueden solucionar con la mediación, creando de diferentes maneras el mejor impacto social e implementando la mediación como la solución a los desacuerdos, que llegan a solucionarse con voluntad de las partes. 


\section{Conclusiones}

A pesar que nuestra Constitución establece a la mediación como Método Alternativo de Solución de Conflictos, sigue existiendo el recelo por parte de los Jueces de sugerir una derivación procesal a la mediación contradiciendo la razón de ser de esta vía, que no es más que descongestionar el sistema de justicia, por la errada idea que serán sancionados por excusarse de sus labores como operadores de justicia; sin embargo, nos encontramos frente al imperante deber del juez garantista de aplicar por sobre todo la Constitución, respetando la posibilidad de utilizar los Métodos Alternos de Solución de Conflictos y de decidir objetivamente por la vía de la mediación cuando lo crea necesario, para transformar la deficiente experiencia que viven los usuarios en el sistema de justicia: en celeridad, transparencia y eficiencia, con el único objetivo de materializar el reconocimiento de los derechos previstos en la Constitución.

La mediación en el sector público es una herramienta que posibilitaría al Estado ahorrarse mucho tiempo y dinero en juicios que la mayoría de las veces se pueden evitar, superando la antigua creencia de que el Estado tiene que utilizar todos sus recursos y poder para exigir al administrado y/o contratista que cumpla, sin tomar en consideración los inicuos recursos que utiliza para ello.

Los medios alternativos de solución de conflictos como la mediación fortalecen la seguridad jurídica en el país pues constituyen una base de confianza de muchos sectores sociales y económicos que desean invertir en nuestro país como sucede en el mencionado caso de la contratación pública. Finalmente, no basta con solo reconocer a la Mediación y otros métodos alternativos de solución de conflictos en la norma, sino es responsabilidad del Estado darle un empuje para su difusión e implementación.

\section{Referencias bibliográficas}

Alvarado, L., y García, M. (2013). Características más relevantes del paradigma socio - crítico: su aplicación en investigaciones de educación ambiental y de enseñanza de las ciencias sociales. Revista Universitaria de Investigación, 9(2), 187-202. Recuperado de http://www.redalyc.org/pdf/410/41011837011.pdf

Burneo, A. J. (2011). La mediación como requisito previo para descongestionar a la justicia ordinaria en cuestiones de interés público. Quito: Universidad Andina Simón Bolívar.

Coleiro, Juan Pedro y Rojas, Jorge A. (1998). Mediación Obligatoria y Audiencia Preliminar, Ediciones Rubinzal y Culzoni, Buenos Aires, Argentina.

Folberg, J. (2012). Mediación: Resolución de Conflictos sin Litigio. México: Limusa.

García Rodríguez, F. (2004). La conciliación en derecho administrativo, ¿un reto para la justicia administrativa?, Bogotá, primera edición, Departamento de Publicaciones, Universidad Externado de Colombia.

Martínez, M. (2014). Ciencia y arte en la metodología cualitativa. (2a ed.). México: Trilllas.

Moderne, F. (2004). Apuntes de Derecho Administrativo Comparado, Bogotá, Universidad del Rosario, 2004, 1a. ed., p.11.

Moore, C. (2010). El Proceso de Mediación. Ed. Granica, Buenos Aires - Argentina, 


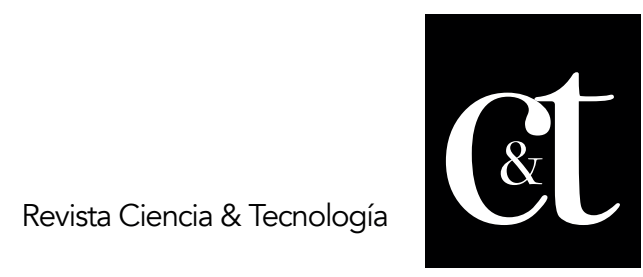

No. 19, 31 de julio de 2018

ISSN impreso: 1390 - 6321

en www.conflictología.net

Murillo, J. (2014). Metodología de Investigación Avanzada. La entrevista. Recuperado

de https://uam.es/personal_pdi/stmaria/jmurillo/Met Inves Avan/Presentacion es/Entrevista_(trabajo).pdf

Taylor, S.J. y Bodgan, R (2014). Introducción a métodos cualitativos de investigación. Barcelona: Paidos.

Zelaya, I., Kuesterman, A. y Armas, C. (2013). Calidad de la mediación, teoría versus práctica. La mediación: alternativa para el sistema de justicia. Revista Momento 28(5). Recuperado de https://s3.amazonaws.com/asiesbooks/books/20135.pdf 